\title{
Radiation scleral necrosis simulating early scleromalacia perforans
}

\author{
J. M. CAPPIN \\ Moorfields Eye Hospital, City Rd., London, E.C.I
}

Few cases of scleral necrosis resulting from radiation have been reported in the ophthalmic literature. This case is of interest because of the diagnostic problem it posed on presentation, in the absence of a history of exposure to radiation (elicited at a later date), and also because of the relatively low radiation dose received.

\section{Case report}

12 years ago, when the patient, a white man now aged 53 years, was living in South Africa, both eyes became inflamed and painful, the inflammation being localized simultaneously to small areas on both sides of the limbus of each eye. A diagnosis of pterygia was made, and the four affected triangular areas of conjunctiva were excised with the apices towards the canthi. There was no evidence of scleral excavation and much of the episcleral tissue was still present. Each area was given I, Ooo rads beta rays from a Strontium 9o source SIA.6 (from Amersham). The active field was $12 \mathrm{~mm}$. in diameter and the applicator $15 \mathrm{~mm}$. in diameter. The dose was repeated $48 \mathrm{hr}$ later and a week and then a fortnight later, making a total dose of 4,00o rads at each site in 16 days.

The patient was asymptomatic until 6 years ago when he suffered several recurrent attacks of these symptoms, lasting 3 to 14 days, with remissions of 4 to 12 days. He has been under observation at Moorfields Eye Hospital over the last 3 years, when several episodes of episcleritis around the lesions have been seen.

The patient was a healthy man, the only abnormality on general examination being slight swelling of the lower end of the left ulna. No xanthelasmata or tophi were present.

\section{Ocular findings}

The visual acuity was $6 / 6$ in each eye unaided; the lids, lashes, lacrimal system, and ocular movements were normal. Neither eye was grossly inflamed. In both eyes, 3 to $4 \mathrm{~mm}$. from either side of the limbus, was a discrete area of scleral excavation, most marked in the lateral part of the left interpalpebral fissure (Fig. I). A few dilated episcleral vessels encircled or approached the edge of

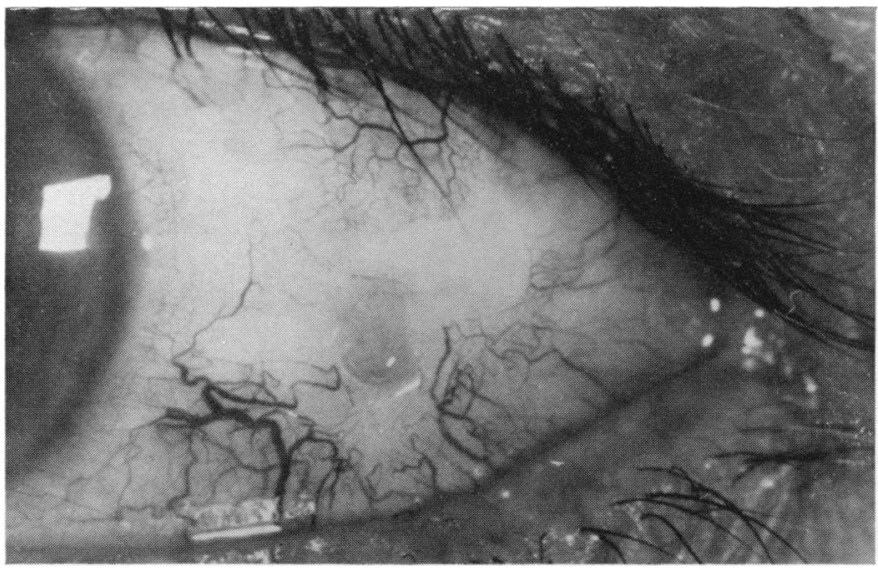

FIG. I Left eye, showing scleral pit on lateral side 
these scleral pits, which were otherwise white and avascular, the blue choroid being visible through the thin sclera (Figs 2 to 4 ). The cornea showed no abnormalities, or evidence of scarring from the previous removal of "pterygia". Except for congenital "blue-dot" lens opacities, and a few drusen near the left macula, the eyes were normal. Intraocular pressures were $15 \mathrm{~mm}$. $\mathrm{Hg}$ in the right eye

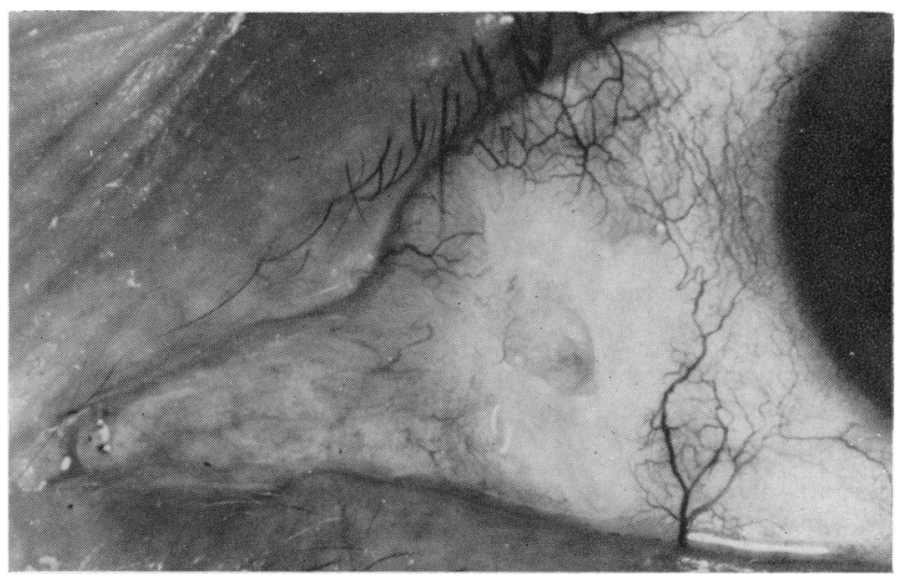

FIG. 2 Left eye, showing scleral pit on medial side

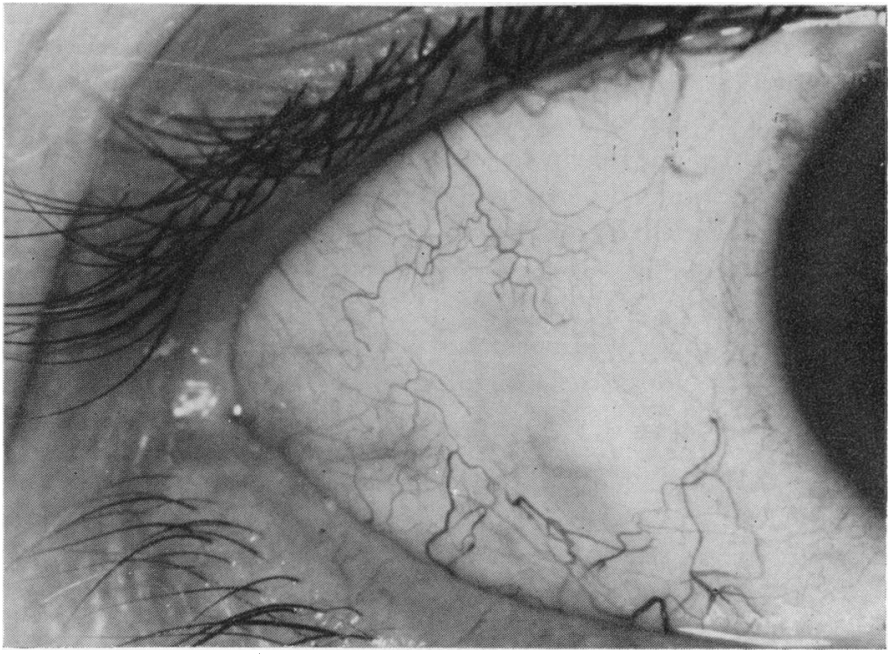

FIG. 3 Right eye, showing avascular area on lateral side of sclera

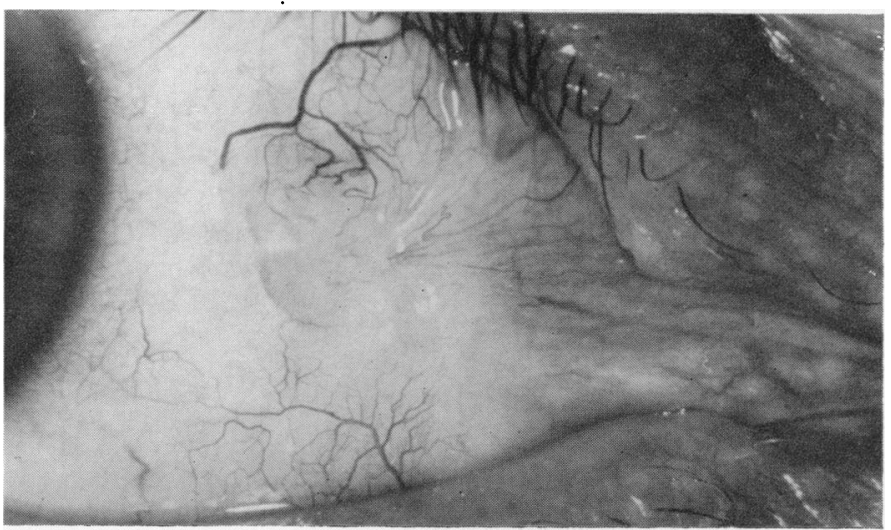

FIG. 4 Right eye, showing scleral pit on medial side 
and $16 \mathrm{~mm} . \mathrm{Hg}$ in the left, measured by applanation. Excluding mild episcleral injection around the lesions on two occasions, no changes have been observed in the lesions during the last 3 years.

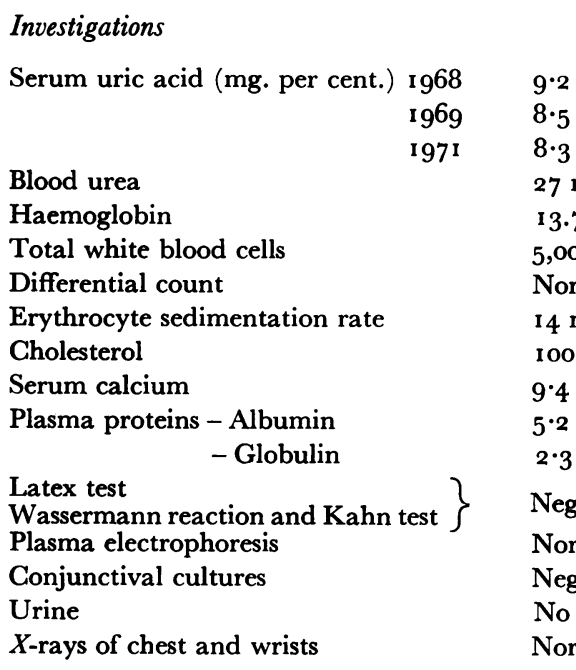

\section{Discussion}

When the patient first presented, either a rheumatoid origin or alternatively ochronosis was suggested for the scleral lesion, as we were then ignorant of the patient's exposure to radiotherapy. The only abnormality found on investigation was a persistently raised serum uric acid level. The patient had bilateral pterygia with a superimposed recurrent episcleritis, possibly of gouty origin. There was no apparent damage to the episcleral tissues resulting from the surgery, as the conjunctiva with pterygia was apparently dissected free, leaving the episclera intact. Only after radiotherapy did the scleral atrophy develop.

Jones and Reese (1953) quote three cases of focal scleral necrosis after radiotherapy; one case had only been exposed to I,500 rads but the others had about I0,000 rads. Stallard (1966) reported two cases out of a series of 100 (treated with radiation) who developed scleral sloughing after treatment with a $15 \mathrm{~mm} .{ }^{60} \mathrm{Co}$. applicator, the sclera receiving a calculated dose of up to 80,000 rads. MacFaul and Bedford (1970) also mentioned a case of scleral necrosis which developed when a $15 \mathrm{~mm} .{ }^{60} \mathrm{Co}$. plaque was applied in the same site on two occasions. They also say "scleral necrosis occasionally followed the use of radon seeds or tantalum wire implants". Sevel (1968) found on examination of eyes enucleated for retinoblastoma that five out of thirteen cases who had received 3,000 to 4,00o rads showed scleral thinning and scarring. Kunz and Lommatzsch (1966) subjected rabbit eyes to $\beta$-irradiation and demonstrated diminished ${ }^{35} \mathrm{~S}$-sulphate uptake by the sclera at doses as low as 50 rads, early disruption of the scleral lamellae at roo rads, and loss of scleral cells with leucocytic infiltration at 500 rads. Cameron (1972) reported a case (No. 2) in which scleral necrosis resulted from a dose of 2,200 rads after removal of a pterygium. This patient had ocular ischaemia due to systemic hypertension.

It is evident that the sclera, regarded so often in the past as being resistant, may be susceptible to relatively low doses of radiation. Cases with underlying scleral vascular disease or inflammation, such as our patient or that of Cameron (1972), may be even more liable to radiation damage. Clinically significant scleral damage occurs only with high 
doses; lower doses, such as those employed in the treatment of retinoblastoma, are of lesser significance and not evident on examination unless localized to the anterior portion of the eye as in this case.

\section{Summary}

This is a case report of scleral necrosis resulting from localized $\beta$-irradiation of 4 , ooo rads after pterygium surgery. Pre-existing episcleritis was probably a contributory factor.

I should like to thank Mr. J. H. Redmond Smith for permission to publish this case, and Mr. P. MacFaul and Mr. M. Bedford for their constructive comments.

\section{References}

CAMERon, M. E. (1972) Brit. J. Ophthal., 56, 52

JONES, I. S., and ReESE, A. B. (1953) A.M.A. Arch. Ophthal., 49, 633

kUnz, J., and Lommatzsch, P. (1966) v. Graefes Arch. Ophthal., 171, 68

macfaul, P., and Bedford, м. A. (1970) Brit. F. Ophthal., 54, 237

SEVEL, D. (I 968 ) Ibid., 52, 453

STALlARD, H. B. ( I966) Ibid., 50, 147 